\title{
L2 vocabulary learning motivation by Chinese EFL learners
}

\author{
Xuan Wang \\ Department of Languages, Literatures and Linguistics, Syracuse University, US \\ https://doi.org/10.36505/ExLing-2020/11/0054/000469
}

\begin{abstract}
L2 motivation has been proved by a plethora of studies to positively affect various domains of L2 learning, among which L2 vocabulary learning is relatively underexplored in the literature. This study, therefore, explores the characteristics of L2 vocabulary learning motivation by Chinese EFL learners and investigates how motivation relates to self-regulated learning strategies. The study employs a mixedmethod approach with 47 Chinese EFL learners. Two instruments, the motivation questionnaire and the learning strategies questionnaire were employed, and ten participants were interviewed with regard to self-regulated vocabulary learning. The results reveal the instrumentality (i.e. promotion and prevention) of Chinese EFL learners in vocabulary learning, which is related to their learning strategies and selfregulation.
\end{abstract}

Keywords: L2 Motivation; Vocabulary Learning, Self-regulation; Learning Strategies

\section{Theoretical background}

L2 motivation, as an intricate construct of individual differences, plays a vital role in the L2 learning performance and learning outcome (Dörnyei \& Ushioda 2009). Over the last three decades, motivation studies underwent three main phrases of research development (Boo et al. 2015). The first phase of motivation studies centred on the social-psychological perspective of language learning; during this phrase, Gardner (1985) proposed the seminal dichotomy of integrative and instrumental motivation. The second phase focuses on the self-determination theory (Deci \& Ryan 1985) from the perspectives of cognitive and educational psychology, according to which, intrinsic (e.g., internal enjoyment and interest) and extrinsic motivations (e.g., external rewards) are two constructs of L2 motivation. The third phase is a key period in which most current motivation studies were conducted; it emphasizes the contextual and dynamic features of learner motivation in relation to the L2-self. One milestone theory, the L2 Motivational Self System (LMSS), was proposed by Dörnyei (2005) which explains the three facets of L2 motivation: Ideal L2 self, Ought-to L2 self and L2 learning experience.

The LMSS has been adopted as the theoretical framework in many current studies that explore L2 motivation characteristics and the effects of motivation on L2 learning. Yet most motivation studies focus on the overall language skills

ExLing 2020: Proceedings of $11^{\text {th }}$ International Conference of Experimental Linguistics, 12-14 October 2020, Athens, Greece 
rather than a specific domain of language. There are only a few motivation studies exploring how L2 motivation influences the development and learning of speaking, writing, listening and reading. Likewise, vocabulary learning motivation did not receive much attention in the pertinent literature. In addition, as L2 motivation explains learners' active and persistent learning, it should reflect on the learning process in particular the use of certain learning strategies. Studies on language learning strategies are mainly in line with the taxonomy by Oxford (1990) which includes four main types: cognitive, metacognitive, social and affective strategies. Yet how L2 motivation is related to these strategies remains underexplored. More recently, self-regulation has received increasing attention in SLA literature (e.g., Csizér \& Tankó 2017), which is a closely related construct to L2 motivation and learning strategies. Thus, it is of great value to study the possible relationship between these variables.

Based on the reviewed scholarly literature, it can be seen that there is limited research on L2 vocabulary learning motivation even though it is well acclaimed as essential for successful L2 learning, especially in an acquisition-poor environment such as the EFL context in China. Moreover, how do L2 motivation reflects on the learning strategies and self-regulation still needs more explorations in the scholarship. Therefore, the present study aims to explore the characteristics of L2 vocabulary learning motivation and investigate how learning strategies and self-regulation are related to the L2 motivation.

Methods

The study employed a mixed-method approach with 47 college EFL students from Beijing, China, among whom 10 students had semi-structured interviews with the author. During the data collection procedure, two main instruments were used for quantitative data collection, namely a motivation questionnaire and a learning strategies questionnaire. The motivation questionnaire was adapted based on LMSS as well as the study by Taguchi et al. (2009). There are 5 scales with 42 items exploring the characteristics of L2 motivation: intrinsic motivation (8 items), instrumentality-promotion (11 items), instrumentalityprevention (8 items), ideal L2 self (8 items) and ought-to L2 self (10 items). These scales were tested in relevant studies (e.g., Taguchi et al. 2009) to be context-matched with the present study. The learning strategies questionnaire contains 28 items that tap into the main types of learning strategies such as cognitive strategies and metacognitive strategies. As for the qualitative data collection, the questions in the semi-structured interviews targeted the vocabulary learning motivation, learning strategies and, in particular, the selfregulation (e.g., What do you think of your willpower to achieve the vocabulary learning goals, if any, which you set for yourself?). Overall, the procedure contains the completion of a background questionnaire and two questionnaires, after that, ten of the participants were interviewed. 


\section{Results and discussion}

The quantitative data were analysed using the principal component factor analysis, and Pearson correlation analysis; and thematic analysis was used to analyse the qualitative data.

The five constructs of motivation in vocabulary learning emerged in this research context with the overall Cronbach's alpha up to .869. Further explorations of these five constructs reveal that two components can be extracted from the instrumentality-promotion, namely promotion-general and promotion-study abroad. These two new factors were not significantly correlated $(r=.093)$, suggesting that they are two separate constructs. The instrumentality is consistent with the literature that, learners from China as well as some other Asian countries, are likely to be instrumentally motivated in language learning. And because the participants in the study were senior college students who were graduating, a large number of them would choose to study abroad, the promotion-study abroad factor thus emerged as one motivational feature.

In this study, the Ideal L2 self was found to be the strongest factor for vocabulary learning whereas the Ought-to L2 self was the weakest one. The mean of these scales were significantly different $(t(46)=12.014, \mathrm{p}<.001)$, which indicates that, for these participants, they learn vocabulary because they want to be better and ideal selves in the future rather than being pushed to. The present study also confirmed the significant correlations between Ought-to L2 self and prevention $(r=.663)$, and between Ideal L2 self and promotion-study abroad $(r=.291)$, which validates the theoretical system of the LMSS by Dörnyei (2005). Besides, Ought-to L2 self was significantly correlated with the promotiongeneral, which is in line with the results in Taguchi et al. (2009) such that in China, young adults after college have to take care of their parents and families as their responsibilities, and so people would like to get promotion and secure higher income to support the families. Thus, Ought-to L2 self and promotion are correlated in this research context.

As regards the vocabulary learning strategies, the study shows that participants did not use many learning strategies to learn vocabulary, and overall, they employed significantly more cognitive strategies than the metacognitive strategies $(t(46)=13.23, p<.001)$. The results also show that the metacognitive strategies are correlated with two promotion factors (e.g., general and study abroad). This result is expected as metacognitive involves more planning, reviewing in the learning process, the "promotion" will then trigger the use of such strategies.

The interview data were transcribed and performed with thematic analysis, and the five aspects (i.e., commitment control, metacognition, sanitation, emotion and time \& environment) of self-regulation were examined. In general, these ten interviewees did not have a high level of self-regulation. More specifically, most of them believed that they did not have strong willpower to 
achieve the vocabulary learning goals and may easily give up their plans and goals. And this is related to their procrastination in vocabulary learning, for example, they may have a plan to learn and review vocabulary but always procrastinate thereby failing to complete the learning goals. Also, these learners found that vocabulary learning was boring, even though some of them try to learn vocabulary in different ways such as using mobile applications. Besides, participants would eliminate the negative surroundings such as going to the study room in the library or other quiet places to learn vocabulary. Therefore, we can see that these participants had a low self-regulated capacity in learning vocabulary, they lack commitment control and metacognitive control; procrastination was a serious problem they have. Yet, they would control the sanitation and emotion in the learning process.

In conclusion, this study explored and confirmed the instrumentality of Chinese EFL learners in vocabulary learning and further revealed two components of instrumentality promotion. The motivation characteristics are related to learners' use of learning strategies and their self-regulated behaviours. Pedagogical implications can be drawn from the study that more attention should be paid to the vocabulary learning motivation and learning strategies of Chinese EFL learners, even though in the senior year, they still need to learn English vocabulary for some instrumental reasons, and some of them may have issues in this learning process, thus some guidance and instructions are necessary to be provided for students to facilitate the vocabulary learning.

\section{References}

Deci, E.L., Ryan, R.M. 1985. Intrinsic motivation and self-determination in human behavior. London: Plenum Press

Dörnyei, Z. 2005. The psychology of the language learner: Individual differences in second language acquisition. Mahwah, NJ: Lawrence Erlbaum.

Dörnyei, Z., Ushioda, E. (eds.) (2009). Motivation, Language Identity and the L2 Self. Bristol, UK: Multilingual Matters.

Gardner, R.C. 1985. Social psychology and second language learning: The role of attitudes and motivation. London: Edward Arnold Ltd.

Oxford, R.L. 1990. Language Learning Strategies: What Every Teacher Should Know. New York: Newbury House.

Taguchi, T., Magid, M., Papi, M. 2009. The L2 motivational self system among Japanese, Chinese and Iranian learners of English: A comparative study. Motivation, language identity and the L2 self, 36, 66-97. 